\title{
OS INTÉRPRETES E A FORMAÇÃO DO BRASIL: OS QUATRO PRIMEIROS SÉCULOS DE UMA HISTÓRIA ESQUECIDA
}

\author{
Dennys Silva-Reis* \\ Universidade de Brasília \\ Marcos Bagno** \\ Universidade de Brasília
}

\begin{abstract}
Resumo: A formação histórica do Brasil muito deveu ao trabalho indispensável dos intérpretes desde o chamado "descobrimento" até bem avançado o século XIX. Neste artigo, destacamos a necessidade de conceder maior visibilidade aos intérpretes e à sua contribuição para a história cultural e linguística do Brasil, de modo que se comece a traçar um retrato mais fidedigno das complexas relações entre línguas, povos e culturas que caracterizaram os quatro primeiros séculos dessa história. Para tanto, destacamos o papel desses agentes culturais para uma reescrita da história da tradução no Brasil. Estes que permanecem marginalizados ou mesmo
\end{abstract}

\footnotetext{
* Doutorando em Literatura no Programa de Pós-Graduação em Literatura na Universidade de Brasília (POSLIT/UnB), Brasília/DF. Mestre em Estudos da Tradução na mesma universidade pelo Postrad (Pós-Graduação em Estudos da Tradução). Bacharel em Letras-Tradução e Licenciado em Língua e Literatura Francesa. Assina o blog Historiografia da Tradução no Brasil (http://historiografiadatraducaobr.blogspot.com.br). E-mail: reisdennys@gmail.com

** Doutor em Filologia e Língua Portuguesa pela Universidade de São Paulo (USP), Professor Adjunto do Instituto de Letras, Departamento de Línguas Estrangeiras e Tradução da Universidade de Brasília (UnB, Brasília/DF). Colaborador do Programa de Pós-graduação em Estudos de Linguagem da Universidade Federal Fluminense (UFF, Niterói/RJ). E-mail: bagno.marcos@gmail.com.
} 
invisíveis na historiografia geral se tornam aqui agentes primordiais para a formação histórica do Brasil em todas as suas etapas.

Palavras-chaves: Intérprete. História do Brasil. Contato linguístico. História da interpretação. Tradução oral.

\title{
THE INTERPRETERS AND THE HISTORICAL FORMATION OF BRAZIL: THE FIRST FOUR CENTURIES OF A FORGOTTEN HISTORY
}

\begin{abstract}
Brazil's historical formation owes very much to the indispensable work of interpreters since the so-called 'discovery' until well advanced the $19^{\text {th }}$ century. In this paper, we highlight the necessity of giving more visibility to interpreters and their contribution to Brazil's cultural and linguistic history, in order to allow us to draw a more trustworthy picture of the complex relations between cultures, peoples and languages that characterized the country's first four centuries. To do so, we emphasize the role these cultural agents have played for a re-writing of the translation history in Brazil. These agent, left aside or even invisible in general historiography, become here fundamental to the historical formation of Brazil in all its phases.
\end{abstract}

Keywords: Interpreter. Brazil's history. Language contact. History of interpretation. Oral translation.

\section{Introdução}

A história do Brasil vem sendo submetida a um profundo processo de revisão neste início do século XXI, o que a faz ser constantemente reescrita e receber novas críticas para além dos paradigmas historiográficos positivistas convencionais (SCHWARCZ, STARLING, 2015). Poderíamos citar aqui, a título de exemplo, a biografia de Mahommah Gardo Baquaqua - The Biography of Mahommah Gardo Baquaqua: His Passage from Slavery to Freedom in Africa and America -, publicada em 2001 nos Estados Unidos e organizada pelo professor Paul Lovejoy e pelo editor Robin Law, que foi traduzida recentemen- 
te para o português no Brasil pelos professores Bruno Veras e Nielson Bezerra, da Universidade Estadual do Rio de Janeiro (UERJ) ${ }^{1}$. Tal obra nos revela um negro letrado, muçulmano, poliglota e não-passivo diante do sistema escravagista do Brasil no século XIX. Seu relato traz à tona novos detalhes sobre a questão do tráfico negreiro e também sobre os negros que lutaram pelo abolicionismo no Brasil.

Também se pode mencionar a recente historiografia da tradução no Brasil iniciada com Lia Wyler (2004), que cada vez mais ganha novos impulsos com os trabalhos de John Milton (2002, 2015), Márcia Abreu (2003, 2008), Dennys da Silva Reis (2012, 2015), Denise Bottmann ${ }^{2}$ (2015), Cristina de Amorim Machado (2012, 2015), Alessandra Harden (2009, 2010), Irene Hirsch (2006, 2008), entre outros pesquisadores. Se, por um lado, o surgimento de novas obras e textos direciona novos rumos para a escrita da História do Brasil, por outro, a metodologia da micro-história proposta por Giovanni Levi (2011) aponta para cada vez mais caminhos ou ramificações das histórias que compõem a macro-história do Brasil. Designamos essas ramificações da História de esferas e nos propomos neste artigo estudar a esfera da história da tradução oral e sua específica relação com a formação do Brasil tanto geográfica quanto sociocultural.

Iniciamos nosso estudo com a seguinte imagem:

\footnotetext{
${ }^{1}$ Informações disponíveis em: < http://g1.globo.com/pernambuco/noticia/2015/05/ livro-conta-jornada-de-escravo-que-era-poliglota-e-viveu-no-brasil-e-eua.html $>$; < http://oglobo.globo.com/sociedade/historia/historiadores-traduzem-unicaautobiografia-escrita-por-ex-escravo-que-viveu-no-brasil-14671795 > . Acesso em 6 de janeiro de 2016.

${ }^{2}$ Vale lembrar que essa pesquisadora mantém, desde 2008, um blogue ("Não gosto de plágio") com textos dedicados às áreas de história, historiografia e história da literatura traduzida no Brasil: http://naogostodeplagio.blogspot.com.br/.
} 


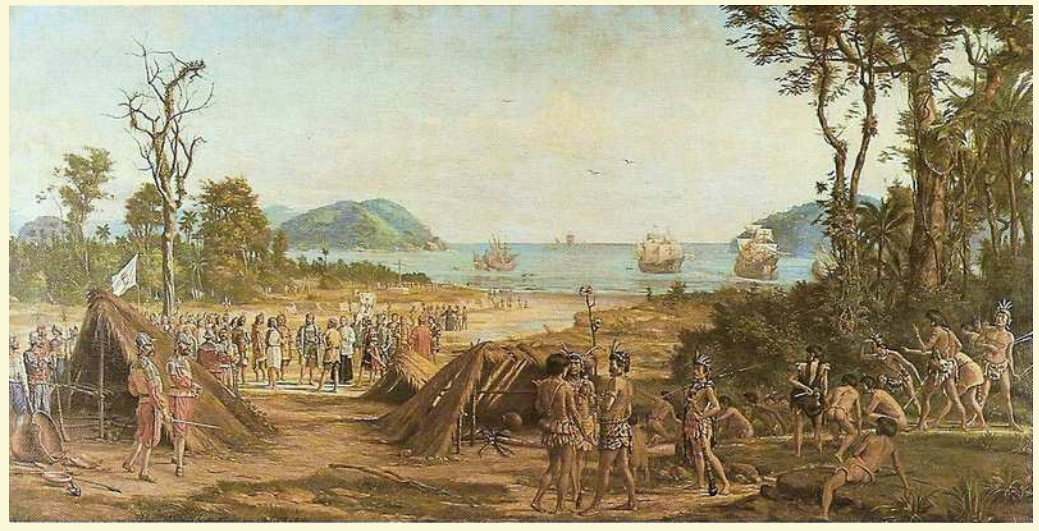

Figura 1: Benedito Calixto, Fundação de São Vicente ${ }^{3}$ (Imagem em Domínio público) Óleo sobre tela, 1900, 385x132cm

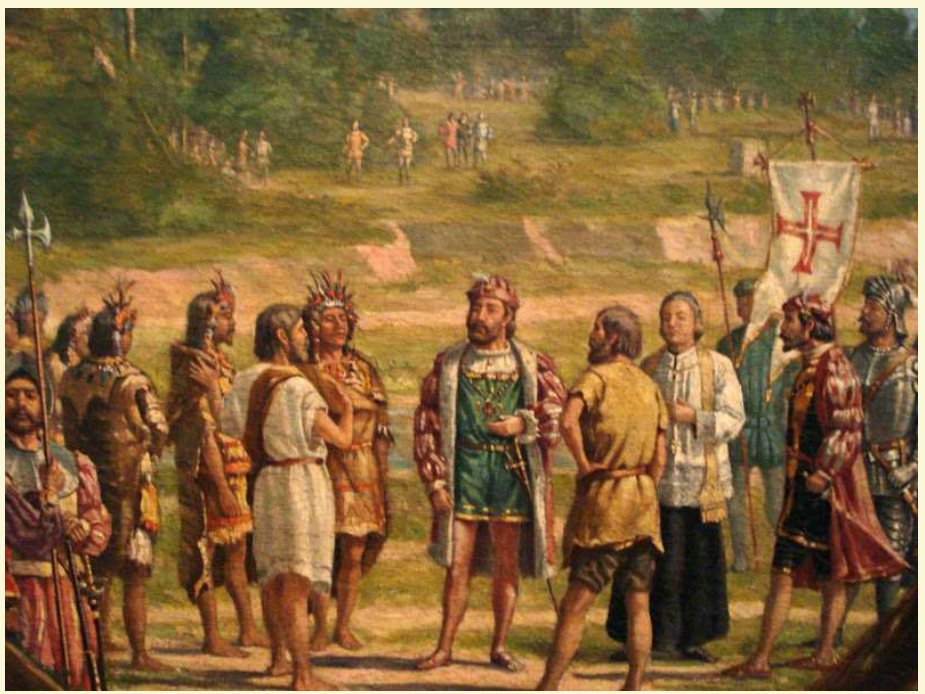

Figura 2: Detalhe à esquerda da imagem (Imagem em Domínio público) ${ }^{4}$

3 Imagem disponível em: <http://www.novomilenio.inf.br/santos/calixt31. htm $>$. Acesso em 21 de julho de 2016.

${ }^{4}$ Imagem disponível em: < http://www.multirio.rj.gov.br/index.php/estude/historia-do-brasil/america-portuguesa/78-do-descobrimento-às-colonizações > 
Esta imagem de Benedito Calixto (1853-1927), inicialmente denominada nos registros antigos como "Desembarque de Martim Afonso de Souza em São Vicente, janeiro de 1532", faz parte das telas oitocentistas que tinham a função de evocar a formação histórica do Brasil no final do século XIX a fim de contribuir para a criação do imaginário do novo Brasil que nascia à época: o Brasil República, ou seja, o Estado brasileiro autônomo e já totalmente independente da metrópole. A tela, que une terra, mar e céu e tem mais de oitenta personagens, conta uma narrativa não-dramática e dispõe como ação principal o diálogo da comitiva de Martim Afonso com indígenas por meio de intermediários que, segundo nossas pesquisas, poderiam ser João Ramalho, Antônio Rodrigues e, possivelmente, Cosme Fernandes Pessoa (o Bacharel de Cananeia). A presença destes intérpretes na obra de Benedito Calixto revela a importância do ato da interpretação e de seu agente (o intérprete) para as conquistas do território português que deu origem ao Brasil.

Percebe-se que a obra pictórica de Calixto - que, convém lembrar, tem uma preocupação histórica e arquivista, além de ser fortemente baseada em fontes documentais - não somente desperta o resgate de informações sobre a história do Brasil, mas também conduz ao imaginário colonial para estimular a invenção de uma história positiva para a nação recém-constituída. Todavia, o que nos chama atenção no trabalho de Benedito Calixto é de que modo os intérpretes desempenharam um importante papel no registro desta história visual do Brasil, algo que a historiografia, ou melhor, a narrativa histórica tradicional brasileira ainda relega a simples citações ou à invisibilidade total.

Ao observarmos a História da Tradução no Brasil, é fato que a tradução oral sempre ocupou a dianteira, ora como simples meio de contato, ora como ofício institucionalizado. Somado a este argumento, sabe-se que a figura do intérprete no percurso secular da história brasileira sempre esteve associada às variadas profissões e ofícios cujos praticantes falavam outras línguas e, consequentemente, se inseriam em outras culturas. 


\section{Século XVI}

No século XVI, a necessidade de comunicação foi premente para os primeiros contatos linguísticos entre portugueses e indígenas, que muitas vezes eram mediados por gestos, imagens e as mais diversas associações linguageiras.

Em meados do século XVI, surgem no Brasil as feitorias, lugares onde se armazenavam os bens da colônia para posterior envio à metrópole. $\mathrm{O}$ acúmulo desses bens, em sua maioria, dava-se pelo escambo, o que em certa medida era possível graças ao língua, uma espécie de intérprete falante das línguas indígenas. O língua aprendia o idioma do índio de maneira forçada, pois, em sua maioria, os que tinham tal ofício no Brasil quinhentista eram degredados ou náufragos, ou seja, criminosos portugueses que eram lançados no meio dos índios a fim de aprender sua língua e depois servir de intérpretes às autoridades portuguesas da colônia (MARIANI, 2007). Conforme explica Faraco (2016: 63),

Os línguas não funcionavam apenas como intérpretes linguísticos, mas também (e principalmente) como mediadores que atuavam quer nos processos de desvelamento, para o europeu, da geografia, da sociedade e da cultura dos territórios visitados ou ocupados; quer nos processos de imposição, às populações locais, da lógica colonial nas relações econômicas, políticas e socioculturais. Nesse sentido, os línguas, pelo seu saber linguístico, dispunham de uma dose de poder que fazia deles agentes cruciais nas sociedades criadas ou recriadas pelo colonialismo europeu. Nas feitorias eram efetivos funcionários da administração e muito bem remunerados.

Os mais famosos línguas desta época são Afonso Ribeiro, João Ramalho e Diogo Álvares Correia (o Caramuru) que muito contribuíram para a sobrevivência dos portugueses com o auxílio dos índios nas novas terras. João Ramalho auxiliou Martim Afonso na 
fundação da cidade de São Vicente em 1532, e Diogo Álvares ajudou Tomé de Souza na fundação da cidade do Salvador em 1549. Embora a História dê maior visibilidade a esses dois homens, convém mencionar que suas esposas - Catarina Álvares Paraguaçu (casada com João Ramalho) e Mbicy (Bartira, Burtira ou Isabel Dias, mulher de Diogo Álvares Correia), ambas índias - talvez tenham sido as duas primeiras intérpretes/intermediárias do Brasil quinhentista, visto que ambas foram as responsáveis por ensinar a língua indígena aos maridos e facilitar seu acesso à cultura autóctone.

A figura do língua também foi importante como a de um agente colaborador durante as guerras quinhentistas entre portugueses e indígenas, mas também entre portugueses e piratas, corsários e outros colonizadores (especialmente, franceses, holandeses e espanhóis) que também tentavam ocupar o Brasil (HEMMING, 2007). Por vezes, alguns índios eram raptados e levados aos países europeus a fim de aprender a língua e os costumes do colonizador e ajudar na conquista das terras almejadas. Era uma prática comum à época e tais índios eram chamados de filhados em contraposição aos lançados - colonos que eram deixados nas terras estrangeiras a fim de aprender a língua dos índios e, logo depois, resgatados para auxiliar na colonização (MARIANI, 2007).

Não se pode esquecer que um dos grandes objetivos proclamados da colonização no Brasil era levar a palavra de Deus para os não-cristãos. E como os índios eram pagãos e, além disso, não falavam a língua do colonizador, a interpretação e a tradução foram fortes instrumentos de catequização e, consequentemente, civilizatórios nos moldes da ideologia católica. Muitos foram os jesuítas, franciscanos, beneditinos e mercedários que se instalaram no Brasil e aprenderam a língua tupi a fim de traduzir os ensinamentos bíblicos aos índios em forma de canções e textos teatrais.

Em São Paulo, o jesuíta José de Anchieta (1534-1597) escreveu várias peças teatrais - entre as mais famosas estão Na Festa de Natal, Na Aldeia de Guaraparim e Na Festa de São Lourenço - que eram encenadas para uma plateia de índios e colonos nas línguas tupi, português, espanhol e latim; ou seja, tanto texto 
original quanto texto traduzido, no que se refere às peças de Anchieta, nasciam ao mesmo tempo, pois eram textos de consumo religioso quase que instantâneo por serem utilizados na catequese dos índios e na manutenção da fé cristã entre os colonos em meio à Babel que era o Brasil quinhentista (HERNANDES, 2008). As apresentações dessas peças soavam como interpretações simultâneas, ora feitas pelos padres, ora feitas pelos próprios atores do espetáculo, uma espécie de interpretação performática verbal em que a mensagem nas diversas línguas era muito mais importante que o desempenho cênico.

A prática de tradução de José de Anchieta criou o primeiro paradigma tradutório da história da tradução brasileira: a tradução-redução. A tradução-redução foi um processo de tradução cultural que Anchieta inventou a fim de obter equivalentes e correspondentes em língua tupi dos símbolos religiosos católicos que não existiam na cosmogonia indígena tais como as ideias de diabo, deus, pecado, céu, inferno, confissão, comunhão, entre tantas outras (AGNOLIN, 2007). Nesse processo, não se traduzia com exatidão ideias ou palavras de uma língua para a outra, visto que as culturas eram muito diferentes, mas se tentava alcançar uma margem de sentido compreensível para que a mensagem cristã pudesse alcançar os indígenas em sua língua materna (ALVES FILHO, 2010).

A atividade linguística de Anchieta também o levou a produzir a primeira gramática de uma língua indígena brasileira, Arte de gramática da língua mais usada na costa do Brasil, publicada em 1595, uma descrição da língua tupi que até hoje serve de importante documento para o estudo desse idioma em sua forma quinhentista.

A relação entre catequese e línguas nativas que se verifica no Brasil quinhentista encontra paralelos nos territórios conquistados pelos espanhóis em outras partes do continente americano. Assim como as línguas tupi e tupinambá foram remodeladas pelos missionários religiosos para que se transformassem em instrumentos de catequese, o que fez surgir as duas importantes línguas gerais (a amazônica e a paulista), que desempenharam papel fundamental nos primeiros séculos da história brasileira, também no México se 
documenta fenômeno semelhante. Na península de Yucatán, onde floresceu a imponente civilização maia, um dos projetos da missão evangelizadora foi a criação de uma lengua reducida ("língua reduzida"), uma espécie de "translíngua” (cf. HANKS, 2010), uma versão sistematizada do maia que pudesse servir aos propósitos coloniais. Também lá o termo espanhol lengua (correspondente a língua) foi empregado para designar os indivíduos de origem europeia que dominavam a língua maia. Naquele contexto, porém, as atribuições do lengua eram mais amplas do que as dos línguas no Brasil. Conforme descreve Hanks (2010, p. 10): "Ser lengua significava exibir as seguintes três características: (i) ser falante nativo de uma língua europeia, (ii) ser capaz de falar a língua indígena local e (iii) ser capaz de interpretar do espanhol para essa língua e vice-versa". No entanto, o estatuto do lengua não se limitava a isso: respeitado na hierarquia social, o trabalho era praticado sobretudo pelos religiosos, de modo que "lenguas missionários escreveram dicionários, vocabulários, artes (gramáticas práticas), gramáticas, léxicos, em suma, toda uma gama de estudos linguísticos" (id., ibid.). Todo esse material era empregado para a formação de futuros lenguas missionários.

Outro termo empregado nos contextos coloniais espanhol e português foi ladino, derivado de latino, e que designava, em princípio, a pessoa capaz de falar a língua latina em questão, isto é, o espanhol ou o português. No caso mexicano, ladino se aplicou para descrever "uns pouquíssimos índios altamente instruídos [...] que conseguiam transpor a fronteira do discurso e falar espanhol com competência quase nativa" (HANKS, 2010, p. 18). No Brasil, porém, o termo ladino só foi aplicado mais adiante, a negros africanos que, por diversos motivos, já chegavam com bom conhecimento do português, aprendido na África, ou logo se assenhoreavam da língua. Em contraste com o negro ladino havia o negro chamado boçal, que desconhecia a língua. Os dois termos logo se transformaram em adjetivos que até hoje são empregados no português brasileiro: ladino é "esperto, sabido, finório"; boçal é "estúpido, bronco, ignorante”. A mesma derivação de sentido ocorreu no es- 
panhol ladino: de índio conhecedor da língua dos colonizadores o termo passou a significar, já no período colonial, "astuto".

Sobre a relação entre lenguas e ladinos no território maia no século XVI, Hanks (2010, p. 18) propõe a seguinte figura:

MAIA

ESPANHOL

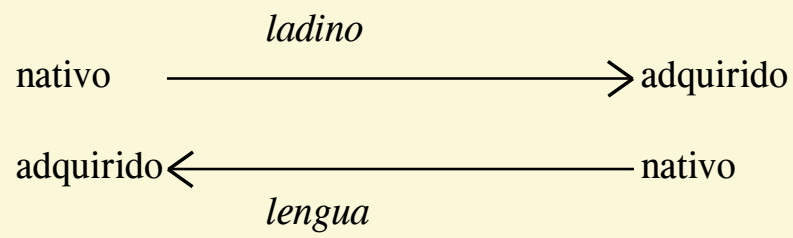

Conforme explica o autor, "ladino e lengua eram termos recíprocos, cada um designando uma competência interlinguística, mas de pontos de vista invertidos" (ibid.). No Brasil, porém, conforme já examinamos, o estatuto do língua era diferente e não surgiu um termo específico para designar cada um dos lados do processo de interpretação. Apesar disso, Anchieta fez questão de atribuir ao língua empenhado na catequese qualidades que o distinguiam de um mero intérprete, conforme se lê em Castro Jr. (2005, p. 137):

As nuanças no ministério catequético mostram que o ofício de "língua" não se limitava à fluência no idioma dos nativos, mas numa carga intelectivo-religiosa e moral apta a fazer, como já se disse acima, migrar noções religiosas de uma língua pródiga em noções abstratas e com uma rica tapeçaria lexical para outra imediatista, com limitações nocionais num léxico de reduzidas proporções. [...] Não eram tais jesuítas, assim, meros intérpretes, mas línguas, distinção anchietana que tem relevantíssima pertinência no estudo da obra jesuítica, já que o termo "intérprete" induz uma mediação em que seu agente não reúne as qualidades de um pregador e todos os seus predicados. 
De todo modo, a distinção entre "língua" e "intérprete" não apresenta a delimitação terminológica e conceitual bem definida no contexto mexicano no caso do lengua e do ladino.

$\mathrm{O}$ estudo atento dos contextos históricos das terras conquistadas pelos portugueses e pelos espanhóis se revela, assim, um campo fértil para a análise comparativa das práticas de interpretação e de seus agentes durante os primeiros séculos dos projetos e dos processos coloniais de cada uma das metrópoles ibéricas.

\section{Século XVII}

O século XVII na história do Brasil tem como marca principal o plurilinguismo. Nessa época existiram, no Brasil, além do território ocupado pelos portugueses na costa brasileira, os territórios ocupados pelos franceses - a França Equinocial, com núcleo na atual cidade de São Luís do Maranhão - e holandeses - a Nova Holanda, que compreendia toda a capitania de Pernambuco. Isso de certa forma determinava um contato ainda maior de línguas e a necessidade quase que imediata de intérpretes para a conquista e a manutenção desses territórios coloniais no Brasil. Inicia-se também a importação de escravos negros da África que, em sua grande maioria, não falavam português. Consequentemente, o número de línguas faladas no Brasil se multiplicava, bem como a necessidade de comunicação por intermédio de intérpretes desses diferentes grupos linguísticos.

Um dos fenômenos seiscentistas mais conhecidos da história do Brasil são as grandes expedições para o interior do país: as entradas e as bandeiras. As primeiras tinham a finalidade de expandir o território e eram financiadas pela Coroa portuguesa; as segundas eram de inciativa privada dos ricos da época com o objetivo de obter lucro. Tais expedições tiveram como agente primordial a figura do língua, que em sua maioria eram índios, grandes conhecedores das terras a serem desbravadas. Entretanto, da metade do século em diante, a esses línguas indígenas somavam-se os línguas euro- 
peus que, com o tempo, se tornaram sertanistas, uma espécie de militar responsável por intermediar junto às expedições os contatos com os novos povos encontrados no sertão do Brasil. Destaca-se ainda que os bandeirantes, em sua maioria, eram filhos de índias com portugueses e falavam a língua da mãe, de modo que já não precisavam de tradutores, diferentemente do que se passava nas entradas. Um dos mais famosos intérpretes desta época é Manuel de Sousa de Eça, considerado um dos grandes línguas do período e importante desbravador e combatente das terras do Ceará, Paraíba, Maranhão, Pará e Amazonas (GODOY, 2002). Frisa-se ainda que a destruição do Quilombo dos Palmares teve como arma secreta o uso de intérpretes, visto que o bandeirante Domingos Jorge Velho, para combinar o ataque aos quilombolas, levou consigo línguas, pois se sentia mais competente em língua geral tupi do que em português (ENDERS, 2008).

Vale também enfatizar que nesse período no Brasil houve um fluxo muito grande de tradutores judeus trazidos pelos colonizadores holandeses. Os judeus que vinham para Pernambuco - a Nova Holanda - eram atraídos pela gratuidade de passagens e de terras e também pela tolerância religiosa e liberdade de culto. Em sua maioria, os judeus que aqui estiveram foram intérpretes - e também, em menor número, tradutores - de holandês, espanhol, francês e português (LEVY, 2008). Os holandeses, que eram protestantes, preferiam os judeus aos jesuítas para tal função, já que consideravam estes últimos como traidores da missão holandesa na nova colônia. Dentre os intérpretes judeus desse período que serviam para as mais diversas funções - desde negociantes nos portos até militares desbravadores de terras - podemos citar Antônio Dias Paparrobalos, Moysés Navarro, Antônio Manuel e David Testa.

\section{Século XVIII}

O setecentismo será definido pela ampliação do território brasileiro, por várias revoltas em todas as regiões do país, bem como 
pelo surgimento de uma noção de identidade brasileira. Além disso, a riqueza, o trabalho e o poder se transferiram do açúcar para o ouro, do Nordeste para o centro da colônia, as chamadas Minas Gerais, que faziam parte da extensa província de São Paulo. A língua portuguesa começa a se unificar e o plurilinguismo do século anterior começa a se dissipar, ora por meio de leis ou proibições, ora pelo genocídio ou expulsão dos falantes de outras línguas que não a portuguesa.

O processo que levou o português a se tornar hegemônico no território brasileiro teve como principal deflagrador o ciclo econômico do ouro. Estima-se, por exemplo, que entre 1700 e 1720, mais de 150.000 pessoas se deslocaram de outras regiões para Minas Gerais, incluindo muitos escravos. De igual modo, entre 1701 e 1760, um verdadeiro êxodo de portugueses se dirigiu para a colônia americana em busca das riquezas proporcionadas pelo ouro: cerca de 600 mil pessoas, sobretudo da região norte de Portugal, se transferiram para o Brasil, o que dá cerca de 10 mil por ano. Para se ter uma ideia da grandeza desses números, basta lembrar que, nos dois séculos anteriores, não mais do que 100 mil portugueses vieram para cá. Tudo isso favoreceu, nas palavras de Lucchesi (2015: 154), a "primeira vaga de lusofonização do Brasil". Na descrição de Faraco (2016: 141),

A progressiva unificação territorial que a descoberta do ouro proporcionou; o deslocamento de grandes contingentes populacionais para a região aurífera; a vinda maciça de portugueses metropolitanos; as redes comerciais que se criaram para o abastecimento das Minas Gerais (unindo o Centro, o Nordeste, o Sul, São Paulo e Rio de Janeiro e, assim, favorecendo o trânsito inter-regional da língua portuguesa); o estabelecimento de uma sociedade urbana em grau até então nunca visto nos espaços coloniais (o que fez surgir e crescer um segmento socioeconômico médio e letrado praticamente inexistente nos séculos anteriores) - todo esse novo quadro econômico e social teve um impacto duradouro na história da 
língua portuguesa no Brasil, seja em sua dimensão dita culta, seja em sua dimensão dita popular.

Apesar do crescente predomínio do português, o ofício de intérprete foi muito valorizado no século XVIII, graças entre outras coisas ao fenômeno do tropeirismo - a travessia de extensas áreas, transportando gado e mercadorias em tropas de cavalos ou mulas até chegar ao local das minas. Os tropeiros se utilizavam de intérpretes para se comunicar com os povos desconhecidos do centro do Brasil, mas esses intérpretes também serviam de elo de comunicação dos inúmeros viajantes europeus que vinham estudar a terra (OLIVEIRA, 2013). De modo semelhante, o movimento das monções - expedições fluviais que partiam de São Paulo para o Mato Grosso a fim de abastecer de mantimentos as minas de ouro - e a procura por drogas do sertão tiveram auxílio dos intérpretes - para o primeiro movimento, o mameluco e o cafuzo; para o segundo, o indígena. Tais expedições de desbravamento foram importantíssimas para o povoamento e enriquecimento dessas terras até então "virgens".

Assim como o ofício de intérprete foi muito valorizado, o ato da interpretação graças ao conhecimento de línguas não-europeias foi um instrumento utilizado em revoltas no século XVIII, além de servir como meio de sobrevivência. Tal como nos descreve Tarcísio Gaspar (2011) ao falar sobre a intervenção de Antônio de Albuquerque Coelho de Carvalho, governador do Rio de Janeiro, na época capital do Brasil, que foi a Minas Gerais a fim de apaziguar os conflitos entre paulistas e imigrantes de outros lugares para a região aurífera, conflitos que fizeram eclodir a Guerra dos Emboabas:

Seja como for, a autoridade não consegue frear os instintos belicosos. Há, inclusive, cilada linguística curiosa, enredada por um carijó paulista, que, escutando as promessas e pedidos do governador, teria dito a outro, em tupi, diante de Albuquerque: "mandemos matar este puto emboaba!". Contudo, o enigma silábico foi rapidamente decifrado pelo português, que já estivera longos anos no Brasil, 
governando o Grão-Pará (1685-1690) e o Maranhão (16901701), e, portanto, sabia a "língua da terra". Percebendo o perigo, o general acatou logo o conselho que lhe fizera um frade, seu companheiro no encontro: "vamos seguindo viagem". Ainda que a história pareça bastante prosaica, mesclando anedotário e ficção, ela descreve temática interessante e rara do conjunto lingüístico colonial. Para além da predominância política e social da língua portuguesa, as falas orais (e, por conseqüência, também as murmurações) possuíam características complexas, misturadas que eram a linguagens não européias, articuladas pelos índios nativos e pelos escravos africanos. Quando estas vozes marginais assumiam conotação política, elas podiam desferir conteúdos perigosos, agravados ainda pela exclusividade de seus significados - como sucedeu no caso acima. Mas a história de Minas também conheceria, afinal, quanto aos escravos, como o uso secreto dos dialetos africanos permitia conspirar signos e arranjos de revolta, sem que os europeus sequer desconfiassem do palavreado. (p. 54)

Com efeito, ao nos inteirarmos da história da tradução escrita do Brasil, percebemos que o século XVIII é repleto de rebeliões (como a Inconfidência Mineira), agitações e motins oriundos, especialmente, das ideias iluministas que desembarcavam clandestinamente e que contavam com o auxílio da tradução. Entretanto, o ato da interpretação, bem como seu agente, o intérprete, eram armas de defesa pessoal e coletiva, além de uma das estratégias de mediação, colonização e, por vezes, de conspiração.

\section{Século XIX}

Antes de mencionarmos, especificamente, a interpretação no século XIX brasileiro, convém fazer uma referência ao imaginário criado em torno da figura do intérprete e do ato de interpretação que pairava entre os portugueses ou, especialmente, entre os deten- 
tores de poder nas ex-colônias portuguesas, tais como os missionários religiosos. Conforme assinala Faraco (2016, p. 66),

os línguas eram indispensáveis (face à diversidade linguística com que os portugueses iam fazendo contato); eram raros (dependiam, em geral, de ser aprisionados e de aprender por imersão a língua de seus captores, o que é sempre um processo demorado nos adultos) e, por isso, muito valorizados, embora não fossem sempre inteiramente confiáveis. (grifos nossos)

Essa relação ambivalente com o intérprete - necessário mas não de todo confiável - vai percorrer toda a história colonial. Um exemplo, no século XVIII, nos vem do relato de um jesuíta chamado João Daniel (2004 [1757-1783]), ativo na região amazônica, que fala dos "descimentos dos índios", ou seja, de expedições conduzidas por missionários com o objetivo de trazer índios das aldeias para as missões, onde seriam catequizados:

A melhor indústria de que usam alguns missionários para estes descimentos dos índios bravos é o procurarem haver primeiro alguma pessoa da nação que querem praticar, especialmente algum menino; mas basta qualquer adulto, porque com afagos e mimos o vão domesticando nas missões até que, afeiçoados aos missionários, os levam estes consigo bem nutridos, regalados e vestidos, quando vão praticar a sua nação, a qual vendo seu parente tão bem tratado, e por outra parte praticados pelo padre, mais facilmente se deixam convencer, e se resolvem a sair, muito mais vendo que os ditos parentes lhes dizem bem das missões, que antes querem voltar para elas do que ficar com eles. É bem verdade que às vezes estes mesmos que os missionários levam para seus fiéis viram da parte dos índios e os praticam pelo contrário, dizendo-lhes a pensão que têm nas missões de servirem aos brancos, os castigos com que são tratados, e 
outras práticas com que totalmente os esfriam; e por evitar semelhantes contingências procuram os missionários tê-los contentes, e se desconfiam deles, não os levam consigo. (DANIEL, 2004, p. 62-63)

O mesmo sentimento de desconfiança imperava nas outras regiões do mundo colonizadas pelos portugueses. Assim, Bernardo Maria Cannecattim, frade capuchinho italiano da província de $\mathrm{Pa}$ lermo, missionário apostólico e prefeito das missões de Angola e Congo, escreveu o Diccionario da Lingua Bunda ou Angolense, explicada na portugueza, e na latina impresso em Lisboa em 1804. A obra conta com um prefácio muito pertinente a respeito do imaginário sobre o intérprete. Vejamos o primeiro trecho ${ }^{5}$ :

Daqui nasce: sujeitarem-se precisamente ao uso dos interpretes, pelos quaes se persuadem entenderem, e serem entendidos do Povo. Fazendo estes homens hum adminiculo indispensavel no ministerio da Palavra, e na propria administração dos Sacramentos. Porém, eu não posso mostrar, sem huma viva dor, a insufficiencia, e os males gravissimos deste meio na pratica da Religião em Angola, como eu mesmo vi, e experimentei.

Os interpretes são Negros do Paiz, gente bruta, que ignora da sua propria Lingua huma grande parte, e que da Portugueza apenas sabe os termos mais vulgares e usuaes. Por estes homens, ou por estes brutos, se ha de annunciar ao Povo a Doutrina da salvação nos seus Dogmas, e na moral, mas succede, frequentemente, que huns taes interpretes, ou não, percebem a força, e o verdadeiro espírito das palavras portuguezas, ou não sabe achar, e escolher na sua Lingua termos, que propriamente lhes correspondão, de que póde resultar o ensinar erros substanciaes, assim a respeito do que devemos crer, como do que devemos obrar.

Além desses horrorosos males, he visivel que as instrucções

5 Transcrevemos este trecho e o seguinte tal como vêm impressos na obra, conservando portanto suas eventuais incorreções ortográficas e de pontuação. 
communicadas por interpretes, e taes interpretes, aos Fieis, ou seja no Tribunal da Penitencia, ou na Cadeia da Verdade, perdem huma grandissima parte de sua energia, e de seu fructo, passando pela languida expressão de um bruto Negro, em cuja boca fica, como suffocada, a semente Evangelica.

Os admiraveis effeitos, que produz no auditorio aquella acção, ou representação, que a Arte de orar chama eloquencia do corpo, inteiramente se invertem e inutilizarão com a interrompida, fria, e maquinal pronunciação dos interpretes: de maneira que a sonora, e tocante voz do Evangelho se faz como insipida, e dissonante pela indisposição do órgão que a communica; e a agua pura, e vivificante da Palavra contrahe huma especie de vicio, e sordidez no infecto canal, por onde transita. (p. II-III)

Essa prevenção contra o ofício do intérprete também marcou a colonização espanhola das terras americanas. Conforme relata Hanks (2010, p. 18):

Por ser estrangeiro, o ladino não tinha a mesma credibilidade com a língua espanhola desfrutada pelo lengua europeu. [...] índios ladinos não eram universalmente apreciados pelos espanhóis. Se o lengua era erudito e confiável, o ladino era escorregadio e ambíguo.

Os intérpretes, assim como o ato da interpretação, sempre foram alvo durante todo o período colonial das missões evangelizadoras das mais diversas Igrejas (católicas ou protestantes). O fato dos intérpretes serem os únicos elos entre os povos recém-contactados e os colonizadores, em particular os missionários, inquietava bastante os representantes eclesiásticos, visto que jamais um não-cristão, segundo eles, poderia transmitir com o mais alto ardor a mensagem evangélica. Daí a necessidade de aprender a língua dos nativos da terra, bem como proporcionar meios para que os demais 
irmãos de congregação pudessem também aprender a língua para bem realizar sua missão cristã. Enquanto tais instrumentos ainda eram inviáveis e poucos eram os cristãos-intérpretes, muitos dos índios e negros brasileiros (e das outras colônias) foram colaboradores de peso das missões evangélicas, o que incluía intermediar os sacramentos, como por exemplo, a confissão. Entretanto, esses intérpretes, conforme constatamos no prefácio de Cannecattim, eram muito mal vistos. Úteis, mas com reservas. Instrumentos imperfeitos, primeiramente, por não serem "legítimos" cristãos e, em segundo lugar, por aprenderem o ofício da intepretação com a experiência de vida.

Ainda no prefácio de Bernardo Maria Cannecattim, ao justificar por que escrever um dicionário da língua bunda, encontramos um discurso pormenorizado sobre os negros intérpretes:

Pouco he necessario meditar, para se conhecer, quanto convem que aquelles aos quaes está incumbido o governo e a administração da Justiça em qualquer paiz, saibão o idioma que nelle se falla. Se taes pessoas não tiverem esta intelligencia, constituem-se na indispensavel necessidade dos interpretes, e, em consequencia, na precisão de indagarem, e saberem por outrem o que muitas vezes o bem público, ou particular exigia, que ellas por si mesmas inquirissem, e soubessem. O importantissimo segredo das disposições politicas, e militares he forçoso que frequentemente seja entendido de hum interprete, (isto he, de um preto venal), ficando exposto a ser revelado, ou por huma simples facilidade, ou por hum insignificante premio.

Quantas vezes o acerto, e felicidade de uma operação militar, em que se interessa a defensa commum ou vencimento de uma batalha, está dependente da exploração, intelligencia, e fidelidade dos interpretes? E será justo que homens de tão pouca instrucção, e confiança sejão instrumentos necessarios do bem, e conservação pública?

Todas as representações, ou requerimentos, que a populosa Nação dos Abundos faz aos Chefes do Governo, lhes são 
declarados pelos interpretes: mas, se o pretendente, ou a súpplica não he do agrado do interprete, está no ponto de ser por este illudida, representando-a diversa; pondo assim, ao mesmo tempo, em ludibrio a authoridade de quem manda, e a justiça de quem pede.

O processo, tanto civíl, como criminal, dos Abundos, he igualmente feito pelo ministerio dos interpretes, sendo por elles explicadas as testemunhas, que fazem a prova do direito das partes, e o fundamento do julgado. Mas, oh quanto arriscada não é a administração da Justiça! Se o interprete está apaixonado, ou vencido contra qualquer litigante, elle então vem a ser o arbitro da sua fazenda, da sua honra ou da sua vida, transformando, como quer os ditos das testemunhas.[...]

De tudo, o que fica ponderado, se conclue, que a intelligencia da Lingua Bunda, ou geral do Reino de Angola, he utilissima, e necessaria aos Ecclesiasticos no exercicio do seu ministerio; aos Governadores, e Magistrados na Regencia do Estado, e na Administração da Justiça; aos Chefes Militares no acerto do seu Commando, e na felicidade de suas operações; aos Commerciantes enfim no manejo do seu negocio, sendo uma ruina, e uma desgraça, que todas essas pessoas não vejão o objecto de suas funções senão ao travéz da opaca sombra de um Negro interprete. [...] (1804, p. III -IV)

Tais minúcias do ofício de intérprete não eram particularidades somente dos intérpretes negros em Angola, mas também destes no Brasil e dos indígenas que aqui ainda restavam em contato com os colonizadores portugueses.

Os intérpretes, chegado o século XIX, tiveram várias atividades: negociante, diplomata, militar, assistente jurídico e médico, guia turístico e missionário. Eles foram nessa época os principais elos nos contatos entre comunidades linguísticas de outras nações e as autoridades portuguesas locais. O maior destaque do intérprete será dado sem dúvida na manutenção das comunidades de imigrantes no Brasil, especialmente no ciclo do café em São Paulo e no ciclo 
de povoamento no sul do país, bem como no ciclo da borracha em todo o norte brasileiro (REIS, 2012).

Vimos de que modo foram alvo de inúmeras desconfianças, como também foram os responsáveis por inúmeras mediações durante confrontos armados, conquista de territórios, negociações comerciais e administrativas, casos jurídicos, expedições de descobrimento e catalogação do legado brasileiro, "turismo" etc. Devido a essa necessidade e utilidade, no que concerne à interpretação no século XIX, a primeira constatação a ser feita é que essa profissão é institucionalizada por diversos decretos e em diversos lugares do Brasil (OLIVEIRA, 2005). Apesar da institucionalização da profissão, o que de certo modo fazia com que ela fosse rentável para quem a exercia, o imaginário construído pelos portugueses a respeito da profissão (alguém nunca muito confiável) não colaborava para que os próprios portugueses a exercessem.

Logo, o língua tanto indígena quanto mameluco continua sua atuação nesta época, em especial no norte do país e nas regiões de fronteira. Surge também o tradutor da praça ou, melhor, o tradutor jura[menta]do, que na realidade era um intérprete, muitas vezes militar, que também fazia traduções escritas de documento oficiais. Podemos citar desta época a figura de Liberato Mitchell, imigrante inglês, morador de Maceió, que chegou a ser, depois de tradutor, caixeiro e político (MACIEL, 2011). Muitos imigrantes, também conhecedores de vários idiomas, ao chegarem no Brasil encontravam facilmente trabalho de intérprete como uma profissão transitória até encontrarem outra. É o caso dos muitos judeus que chegaram na República no final do século XIX:

Rubem Israel teve uma desastrosa viagem para Parintins via Santarém, após um mês de travessia do oceano. Estudara, em Lisboa, como ele mesmo conta em suas memórias, até o terceiro ano do Liceu. Quando chegou, dirigiu-se à loja dos tios, Jacques e Moacyr Bentes, para trabalhar como caixeiro. Jacob Aligua chegou ao Brasil com 16 anos, em 1890, dominando vários idiomas e não teve muita dificuldade em 
obter um emprego de intérprete a bordo do cruzador "Nitéroi". Dois anos depois havia abandonado aquela atividade e passara a dedicar-se ao mascate de fazendas. Aliás, a profissão de interprete era comum. Rosa Kornman, uma russa de Odessa, no Brasil desde 1877, sustentava seus dois filhos menores como tradutora e intérprete. (HELLER, 2010, p. 101)

Nesse quadro de intérpretes podemos mencionar igualmente o dragomano ou turgimão (duas palavras derivadas do árabe turguman, "intérprete"), nome aplicado sobretudo ao intérprete de línguas não ocidentais. Geralmente trabalhava como agente diplomático e era uma figura importante para o desenvolvimento das relações internacionais. Os mais conhecidos dragomanos do século XIX são Abdurrahman Al-Baghdadi (1865) - militar de Damasco e imã - e Antônio de Summerer (1859) - que trabalhou nas embaixadas de Portugal e do Brasil no Império Otomano como intermediário do embaixador brasileiro Antônio Alves Machado de Andrade Carvalho (GOLDFELD, 2012).

Cabe ainda mencionar que será também no século XIX que teremos pela primeira vez na história da tradução do Brasil um método para o ensino da interpretação: a obra O Selvagem (1876) do militar Couto de Magalhães. Este livro era direcionado aos intérpretes militares brasileiros no auxílio à vigilância e ao "amansamento" dos índios ainda não "civilizados" e que não sabiam falar nem ler e escrever em língua portuguesa. Seus objetivos eram:

Conseguir que o selvagem entenda o portuguez, o que equivale a incorporal-o á civilisação, e o que é possivel com um corpo de interpretes formado das praças do exercito e armada que fallem ambas as linguas, e que se dissiminariam pelas colônias militares, equivaleria a: $1^{\circ}$ Conquistar duas terças partes do nosso territorio. $2^{\circ}$ Adquirir mais um milhão de braços aclimados e utilíssimos. $3^{\circ}$ Assegurar nossas comunicações para as bacias do Prata e do Amazonas. $4^{\circ}$ 
Evitar no futuro grande efusão de sangue humano e talvez despesas colossais, como as que estão fazendo outros países da América (frontispício).

Ainda dentro do quadro do ensino da interpretação no século XIX, o Colégio Santa Isabel, fundado em 1870 no norte de Goiás (hoje, estado do Tocantins), será o primeiro estabelecimento de ensino da tradução oral. Esse colégio tinha como objetivo formar os índios capturados na região do Tocantins como intérpretes para o auxílio na colonização da região centro-oeste do Brasil (MARIN, 2009). No entanto, o colégio, para o objetivo com que foi planejado, durou pouco tempo devido à evasão de estudantes. Além disso, dos que se tornaram intérpretes indígenas, muitos sabiam falar a língua portuguesa, mas não a sabiam escrever. Também poucos foram os índios que, sabendo a língua do colonizador, contribuíram com o projeto civilizatório do colégio Santa Isabel e da obra de Couto de Magalhães.

\section{Conclusão}

Ao percorremos até aqui, de forma resumida, os primeiros quatro séculos de história da interpretação no Brasil, percebemos a importância dos intérpretes na formação histórica do país e o quanto esta história ainda tem pontos a serem desvendados. A clarificação ou as explicitações da participação dos intérpretes na história do Brasil contribuiriam sem dúvida para diminuir a invisibilidade do agente de interpretação. Tal invisibilidade pode ser explicada, grosso modo, por três motivos: 1) o imaginário da colonização, em que os intérpretes ou o ato da interpretação nunca foram atos/agentes de credibilidade total; 2) o fato de ser uma profissão transitória, que é historiograficamente comprovado pelas diversas biografias que encontramos dos personagens da história que foram em algum momento intérpretes, mas que não exerceram este ofício senão em momentos específicos antes de encontrarem uma ocupação mais 
regular e rentável; e 3) a concepção que se impregnou no senso comum em torno deste ofício, uma concepção segundo a qual é preciso que o discurso emitido na língua fonte seja perfeitamente transposto na língua de chegada, ou seja, fluente como se a mensagem estivesse sendo dita sempre em língua fonte, o que faz com que a pessoa do intérprete seja vista como mero canal da mensagem e não como agente ativo na prática comunicativa.

$\mathrm{Na}$ história da interpretação no Brasil, delineiam-se alguns perfis específicos de intérpretes: o língua, o intérprete militar e o dragomano. O primeiro passou por diversas fases (degredado, náufrago, missionário, sertanista, indígena, mameluco, etc.), mas sempre teve uma vinculação com a língua da terra onde morava e a terra que conhecia bem ou em que era aceito. O segundo foi um dos tipos de institucionalizações do ofício de intérprete - muito mais presente durante o século XIX, mas que também já tivera precedentes nos séculos anteriores - em que, na maioria das vezes, portugueses ou estrangeiros europeus eram obrigados a (ou condecorados por) aprenderem a língua dos nativos da terra a fim de potencializarem a confiança dada aos que exerciam tal serviço. Já o terceiro, que também surgiu no século XIX sem precedentes anteriores, era o sinal do avanço das relações entre o Brasil e outras nações não-europeias - assunto que deve ser mais bem estudado diante das poucas referências que temos.

Se, por um lado, a história da interpretação no Brasil, da qual tentamos esboçar alguns traços aqui, retira a invisibilidade do agente da interpretação desta narrativa, por outro lado ela sinaliza o quanto os intérpretes foram úteis para o crescimento do Brasil culturalmente e geograficamente. Movimentos como os dos bandeirantes, dos tropeiros e das monções, que tinham como uma das finalidades a conquista de novas terras, foram exitosos graças aos intérpretes. A disseminação oral do cristianismo, primeiro passo da evangelização católica no Brasil, foi antes de tudo um registro do trabalho de intérpretes que deixou fortes marcas cristãs no imaginário religioso brasileiro. As primeiras relações diplomáticas de nações não europeias com o Brasil também devem muito à 
intermediação dos intérpretes (evidentemente, até os dias atuais) por exemplo, há relatos de que, no século XIX, dragomanos eram indispensáveis na relação do Brasil com o Império Otomano.

Enquanto há intérpretes há história(s) do Brasil a ser(rem) (re) interpretada(s)!

\section{Referências}

ABREU, Márcia. Os Caminhos dos livros. 1. ed. Campinas: Mercado de Letras/ ALB/FAPESP, 2003. v. 1. 382p .

ABREU, Márcia. Trajetórias do romance: circulação, leitura e escrita nos séculos XVIII e XIX. 1. ed. Campinas / São Paulo: Mercado de Letras / FAPESP, 2008. v. 1.648 p.

AGNOLIN, A. Jesuítas e selvagens: a negociação da fé no encontro catequético-ritual americano-tupi (séc. XVI-XVII). São Paulo: Humanitas, 2007.

ALVES FILHO, P. E. "As traduções do jesuíta José de Anchieta para o tupi no Brasil colonial”. In: Milton, John. TRADTERM, 17: A tradução no Brasil: história, sociedade e política. São Paulo. 2010. p. 11- 30.

BOTTMANN, D.. Bibliografia Russa Traduzida no Brasil (1900-1950). In: RUS - Revista de Literatura e Cultura Russa - Número 4. São Paulo: USP, 2015.

CANNECATTIM, B. Diccionario da Lingua Bunda ou Angolense, explicada na portugueza, e na latina. Lisboa: Impressão Régia, 1804.

CASTRO Jr, J. B.. A língua geral em São Paulo: instrumentalidade e fins ideológicos. Dissertação de mestrado em Linguística. Programa de Pós-Graduação em Letras e Linguística do Instituto de Letras da Universidade Federal da Bahia. Salvador: UFBA, 2005. 
DANIEL, J.. Tesouro descoberto no máximo rio Amazonas. Rio de Janeiro: Contraponto, 2004 [publicação original: 1757-1783].

ENDERS, A.. Nouvelle Histoire du Brésil. Paris: Editions Chandeigne, 2008.

FARACO, C. A.. História sociopolítica da língua portuguesa. São Paulo: Parábola, 2016.

GASPAR, T. de S.. Palavras no chão: murmurações e vozes e Minas Gerais no século XVII. São Paulo: AnnaBlume, 2011.

GODOY, J. E. P.. As alfandegas de Pernambuco. Brasília: ESAF, 2002.

GOLDFELD, M. S.. O Brasil, o Império Otomano e a sociedade internacional: contrastes e conexões (1850-1919). Tese em História, Política e Bens Culturais. Fundação Getúlio Vargas. Rio de Janeiro: FGV, 2012.

HANKS, W.F.. Converting words: Maya in the age of the cross. Berkley/Los Angeles/Londres: University of California Press, 2010.

HARDEN, A. R. de O.. Manuel Jacinto da Gama: Ciência e tradução no final do século XVIII. In: Tradução em Revista 8: Contribuições para uma Historiografia da Tradução. Rio de Janeiro: PUC-RIO, 2010. 1-19.

HARDEN, A. R. de O.. Brasileiro tradutor e/ou traidor: Frei José Mariano da Conceição Veloso. In: Cadernos de Tradução v. 1 n. 23. 131-148. Florianópolis: UFSC. 2009.

HELLER, R. J.. Judeus do Eldorado: reinventando uma identidade em plena Amazônia. Rio de Janeiro: E-papers, 2010.

HEMMING, J.. Ouro vermelho: a conquista dos índios brasileiros. Tradução Carlos Eugênio Marcondes de Moura. São Paulo: EDUSP, 2007.

HERNANDES, P. R.. O teatro de José de Anchieta: Arte e Pedagogia no Brasil Colônia. Campinas: Alínea/Fapesp, 2008. 
HIRSCH, I.. A tradução e a Inconfidência Mineira. In: Tradução em Revista 5: tradução e/na História. Rio de Janeiro: PUC-RIO, 2008.

HIRSCH, I.. Versão Brasileira: traduções de autores de ficção em prosa norte-americanos do século XIX. São Paulo: Alameda, 2006.

LEVI, G. "Sobre micro-história”. In: BURKER, P. (org.). A escrita da história: novas perspectivas. Trad. Magda Lopes. São Paulo: UNESP, 2011.

LEVY, D. T.. Judeus e marranos no Brasil holandês - pioneiros na colonização de Nova York" (século XVII). Dissertação de mestrado em História Social. Universidade de São Paulo (USP), 2008.

LUCCHESI, D.. Língua e sociedade partidas. São Paulo: Contexto, 2015.

MACHADO, C. de A.. Notas sobre as primeiras traduções em língua portuguesa: astrologia e desenvolvimento naútico na Península Ibérica. In: Tradução em Revista 18: Historiografia da tradução no Brasil. Rio de Janeiro: PUC-RIO, 2015.

MACHADO, C. de A.. O papel da tradução na transmissão da ciência: o caso do tetrabiblos de Ptolomeu. Rio de janeiro: Mauad X, 2012.

MAGALHÃES, C. O selvagem: Trabalho preparatório para aproveitamento do selvagem e do solo por ele ocupado no Brazil. Rio de Janeiro: Typ. da Reforma, 1876.

MACIEL, O. B. A.. A perseverança dos caixeiros: o mutualismo dos trabalhadores do comércio em Maceió (1879-1917). Tese em História. Universidade Federal de Pernambuco: UFP, 2011.

MARIANI, B.. Quando as línguas eram corpos - sobre a colonização linguística portuguesa na África e no Brasil. In: Orlandi, E. P.. Política linguística no Brasil. Campinas: Pontes Editora, 2007.

MARIN, J. O. B.. A formação de trabalhadores brasileiros: a experiência do Colégio Isabel. In: História. São Leopoldo: Unisinos, 2009. 
MILTON, J. . O Clube do Livro e a Tradução. Bauru: Editora da Universidade do Sagrado Coração, 2002.

MILTON, J.. "Cartas Chilenas: the Pseudotranslation of Thomas de Gonzaga". In: Tradução em Revista 18: Historiografia da tradução no Brasil. Rio de Janeiro: PUC-RIO, 2015.

OLIVEIRA, J.. Margens escritas: a vida e o trabalho dos remeiros do São Francisco. Caminhos de Geografia. Uberlândia: UFU, 2013. p. 76-90.

OLIVEIRA, L. E. M. de. As origens da profissão de tradutor público e intérprete comercial no Brasil(1808 - 1943). In: Claritas: Revista do Departamento de Inglês da Pontifícia Universidade Católica de São Paulo, 2005. p. 1-16.

REIS, D. da S.. A relevância da tradução no Oitocentos brasileiro. In: Anais do III encontro de História do Império brasileiro: cultura e poder no Oitocentos. São Luís: UFMA, 2012. CD.

REIS, D. da S.. Impactos da Tradução escrita no Brasil do século XIX. In: Tradução em Revista 18. Rio de Janeiro: PUC-RIO, 2015.

SALA, Dalton (org.). Benedito Calixto: Memória Paulista. São Paulo: Pinacoteca de São Paulo, 1990.

SCHWARCZ, L.; STARLING, H. Brasil: uma biografia. São Paulo: Companhia das Letras, 2015.

WYLER, L.. Línguas, poetas e bacharéis: uma crônica da tradução no Brasil. Rio de Janeiro: Rocco, 2003.

Recebido em: 19/04/2016

Aceito em: 29/05/2016

Publicado em setembro de 2016 